\title{
CORRIGENDUM
}

\section{FHIT loss confers cisplatin resistance in lung cancer via the AKT/NF-кB/Slug-mediated PUMA reduction}

D-W Wu, M-C Lee, N-Y Hsu, T-C Wu, J-Y Wu, Y-C Wang, Y-W Cheng, C-Y Chen and H Lee

Oncogene (2017) 36, 5439; doi:10.1038/onc.2017.249; published online 17 July 2017

Correction to: Oncogene (2015) 34, 2505-2515; doi:10.1038/ onc.2014.184; published online 7 July 2014

Since the publication of the above article, the authors have noticed that the PUMA immunostainings in the 'A549 (NC) treated with cisplatin' panels in Figure $4 c$ was incorrect. The authors acknowledged this was the result of administrative error and have provided the correct images for the affected panels. A corrected version of Figure $4 \mathrm{c}$ is below. The results and conclusions put forth in this article remain unchanged.

The authors would like to apologise for this error and the inconvenience this may have caused. c

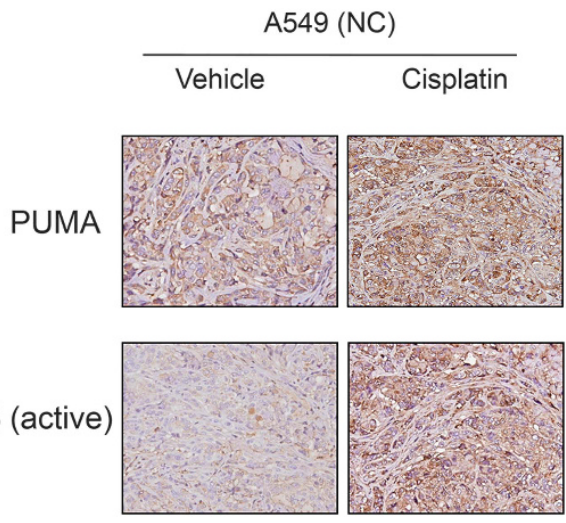

A549 (FHITsi)

\begin{tabular}{|c|c|}
\hline Vehicle & Cisplatin \\
\hline
\end{tabular}

+ Perifosine
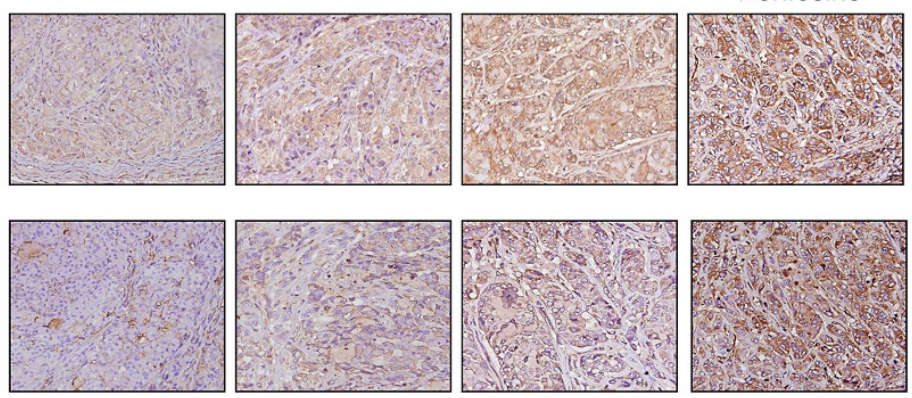

Figure 4. 